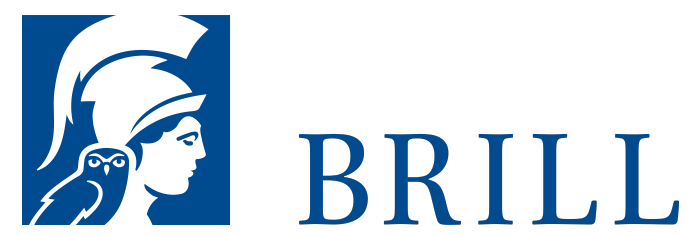

\title{
Offenbare Auferstehung
}

Eine Studie zur Auferstehung Jesu Christi in

offenbarungstheologischer Perspektive

\section{Author: Thomas Peter FÃ $₫$ ÃŸel}

Der Glaube an die Auferstehung Jesu Christi ist zweifellos das zentrale Thema des christlichen Glaubens und bildet deswegen auch die Grundlage fÃ $1 / 4$ r eine zeitgemÃ $\propto$ ÃŸe Offenbarungstheologie der Gegenwart. In kritischer Auseinandersetzung mit theologischen Interpretationen der $\hat{A} » A u f e r s t e h u n g$ Jesu ChristiÂ« rekonstruiert der Autor ein modernes VerstÃåndnis der Auferstehung. Er gewinnt dieses in einer innovativen Auseinandersetzung mit den Texten des zweiten Vatikanischen Konzils und den biblischen Texten. Das Ergebnis ist eine von der Auferstehung her neu gewonnene Theologie der Offenbarung. Deren Zentrum bildet ein $\hat{A} »$ sakramentales Wirklichkeitsverst Ã ondnis $̂$ «, das den christlichen Lebensvollzug als existentiell glaubw Ã $1 / 4$ rdig und gesellschaftlich relevant ausweist. Die Habilitationsschrift entwickelt ihr innovatives Potential aus einer neu entwickelten Verbindung von hermeneutischen, poststrukturalistischen und historisch-kritischen Analyse- und Interpretationsmethoden. Es ist die erste umfassende Studie zum Thema Auferstehung Jesu Christi im deutschsprachigen Raum nach Ã¹/4ber 20 Jahren.

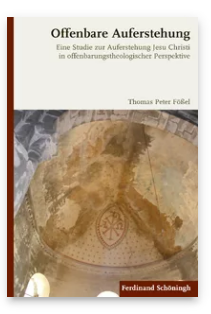

Pages: 659

Seiten, $10 \mathrm{~s} / \mathrm{w}$

Tab.

Language:

German

Subjects:

General,

Theology and

World

Christianity

Publisher: Brill |

SchÃ ๆningh

E-Book (PDF)

Released online: 18 Dec 2017

ISBN: 978-3-

657-78771-5

List price

Paperback

Publication date: 15 Dec 2017

ISBN: 978-3506-78771-2

List price 
Thomas Peter FÃ $\llbracket \tilde{A}$ Ÿel ist wissenschaftlicher Assistent am Seminar fã $1 / 4$ r Fundamentaltheologie der Uni Bonn sowie Dozent fã $1 / 4$ r Fundamentaltheologie am Ã $1 / 4$ berdiÃ |zesanen Studienhaus St. Lambert, Lantershofen.

For more information see brill.com

$$
\begin{aligned}
& \text { Order information: Order online at brill.com } \\
& \text { +44 } 33 \circ 333 \text { o049 | customerservices@brill.com } \\
& \text { Submission information: brill.com/authors }
\end{aligned}
$$

Titles published by Brill | Fink, Brill | mentis or Brill | Schöningh: +49(o)71 5413279216 | brill@brocom.de 